\title{
Investigation of properties of the constant technological track, which is used in bridge agriculture
}

\author{
Adamchuk V. ${ }^{1}$, Bulgakov V. ${ }^{2}$, Kuvachov V. ${ }^{3}$, Holovach I. ${ }^{4}$ Ihnatiev Ye. ${ }^{5}$, Chernysh $0 .{ }^{6}$ \\ ${ }^{1} N S C$ «Institute of Mechanization and Electrification of Agriculture» \\ 11 Vokzalna Str., Hlevakha township, Vasylkiv district, Kyiv oblast, 08631, Ukraine

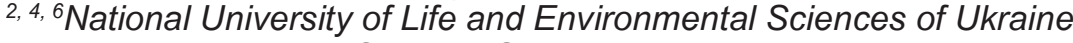 \\ 15 Heroiv Oborony Str., Kyiv, 03041, Ukraine \\ 3, 5 Tavria State Agrotechnological University named after Dmytro Motornyi \\ 18 B. Khmelnytskoho Ave., Melitopol, Zaporizhzhia oblast, 72312, Ukraine

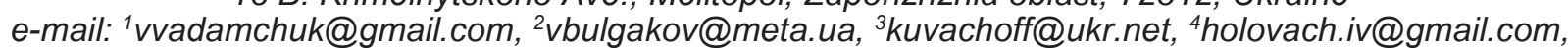 \\ ${ }^{5}$ yevhen.ihnatiev@tsatu.edu.ua, ${ }^{6}$ chernysh@nubip.edu.ua \\ ORCID: ${ }^{1}$ 0000-0003-0358-7946, ${ }^{2} 0000-0003-3445-3721,{ }^{3} 0000-0002-5762-256 X,{ }^{4} 0000-0003-1387-4789$, \\ ${ }^{5} 0000-0003-0315-1595,{ }^{6} 0000-0001-6173-0259$
}

Goal. To determine the physical-and-mechanical properties of soil traces of a constant technological track and their influence on the adhesion and traction of the bridge agricultural vehicle of a new design. Methods. Theoretical research was conducted using the basic provisions of the tractor theory. Experimental studies were conducted in the soil channel according to generally accepted and developed methods using modern laboratory control and measuring equipment. The results of the experimental study were processed by statistical methods on a PC using the basic provisions of correlation analysis. Results. For the bridge agricultural tool of a new design, which was used as an object of experimental research, with repeated passes of its running wheels, it was found that the traces of a constant technological track have density and hardness in the upper soil layer $(0-5$ $\mathrm{cm}$ ), which significantly depend on its humidity. Thus, a high non-linear correlation is established between the hardness and density of the soil trace of the constant technological track, which is approximated by a quadratic dependence. This makes it possible at its practical use to predict the value of the density of traces of a constant technological track based on the results of hardness measurements and vice versa, which will ensure the effective use of the bridge agricultural tool. Besides, to ensure maximum traction and traction of the running wheels of the bridge agricultural vehicle during its movement on the soil track of the constant technological track, it is established that increasing the hardness of the latter requires increasing the air pressure in its tires and vice versa. Conclusions. Study of the properties of soil traces of a permanent technological track shows that with increasing humidity of the soil trace of the track from 10 to $45 \%$, the density in it, i.e. in its layer, which is equal to $0-5 \mathrm{~cm}$, decreases from 1.60 to $1.30 \mathrm{~g} \cdot \mathrm{cm}-3$, hardness - from 4.5 to $2.8 \mathrm{MPa}$. It was also found that with increasing the hardness of the traces of the constant technological track from 1.0 to $3.5 \mathrm{MPa}$, the air pressure in the tires of the wheels of the bridge agricultural vehicle should be increased from 60 to $650 \mathrm{kPa}$, i.e. 10 times. For tire brands used in this bridge tool, the pressure should be $160 \mathrm{kPa}$. Therefore, the effective operation of this bridge agricultural tool with the maximum pressure in the tires of its running wheels is possible only with the hardness of the traces of the constant technological track $2.25 \mathrm{MPa}$ and above.

Key words: agricultural product, soil, theoretical and experimental researches, statistical processing, use of PC.

DOI: https://doi.org/10.31073/agrovisnyk202008-08

The main problem solved in the theory of rolling of the driving wheel of a mobile power vehicle is to improve the quality of its adhesion to the support surface to provide a sufficiently high thrust [1,2].

Coupling of the driving wheel of an agricultural unit with the supporting surface of the trail tracks of a constant tramline is caused by the following forces: friction forces between the ground and the supporting surfaces of the tire; gearing forces occurring when the tire's gruntoshafts stop against the ground; forces acting in the plane of cut of the ground bar located between the gruntoshafts. Coupling of the driving wheel of an agricultural unit with the supporting surface of the trail tracks of a constant tramline is caused by the following forces: friction forces between the ground and the supporting surfaces of the tire; gearing forces occurring when the tire's groundshafts stops with the ground; forces occurring in the plane of cut of the ground bar located between the groundshafts. If the ground support surface is very dense, the friction force between the ground and the tyre support surfaces has a significant influence on the adhesion and therefore the traction of the tyre. As the soil density decreases, the depth of penetration of the grunting gears increases and the ground forces of the tyre grunting gears against the ground and friction in the plane of cut of the ground bar between the grunting gears have a greater influence on the ground surface.

It is also known [1] that the rolling resistance force of wheels of mobile energy means depends on the properties of the soil, characterized by the coefficient of volume compression. This factor is closely correlated with soil hardness. 
On the basis of the aforesaid it is visible, that one of the most important conditions of sufficient grip of wheels of the bridge agricultural unit by a supporting surface and the minimum resistance to rolling is physical and mechanical properties of traces of a constant technological track. The study of its properties is a real basis for ensuring a high coefficient of efficiency of the bridge agricultural units. However, the physical and mechanical properties of soil traces of a constant tramline have not been practically studied.

Analysis of recent research and publications. There is extensive experience in exploratory work aimed at establishing a correlation between soil density and hardness [7-9]. It should be noted that the hardness of the soil is affected not only by its density but also by the humidity, which is unevenly distributed both on the surface of the field and on the depth of the soil [8].

There are two methods of measuring soil hardness - positional and continuous (dynamic) [7, 8]. The positional method of measuring soil hardness involves the use of devices such as hardness testers (density meters) of the Revyakin system. In the positional diagram, the tip of the penitrometer moves perpendicular to the soil surface. Continuous (dynamic) measurement of soil hardness is a tool to intensify the process of removing information about the state of the soil on hardness.

Using positional measurements of soil density and hardness, researchers have established correlations between these indicators in the field [7-9]. An analysis of scientific publications has shown that there is a strong correlation between soil density and hardness. From what it is necessary that by results of measurement of hardness it is possible to predict value of density of soil. But for this purpose every time before and after the end of measurements of hardness and density of soil on the field it is necessary to carry out calibration or comparison of hardness and its density. In case of precipitation during the collection of information it is necessary to repeat the operations of comparing the hardness and density of the soil.

However, the physical and mechanical properties of the soil in the conditions of agricultural agro background significantly differ from the properties of the compacted leveled track of the constant technological track. The latter does not allow the use of existing analytical dependencies that link these indicators. There is almost no information on the evaluation of the properties of the constant technological track. Insufficient research has been conducted in the direction of monitoring the properties of the constant technological track and their influence on the traction and traction of bridge agricultural units.

Purpose of research. The purpose of this study is to study the correlation between the indicators of physical and mechanical properties of the soil trace of the constant technological track and their impact on the adhesion and traction of the bridge agricultural unit.

Research methods. The physical object of experimental research was the bridge agricultural unit of our construction [10] (Fig. 1). This agricultural product has a wheel drive with pneumatic tires of size 9.5R32.

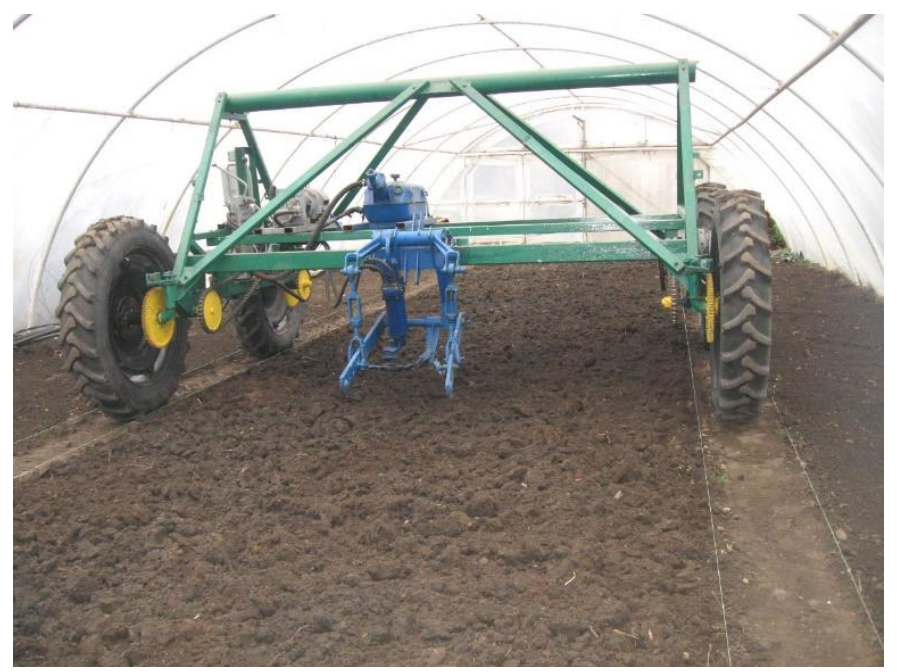

Fig. 1. Bridge agricultural unit with pneumatic wheels moving on soil tracks of a constant technological track

Physico-mechanical properties of the soil in the traces of a constant technological track were measured in the layer thickness of $0 \ldots 5 \mathrm{~cm}$. To determine the hardness of the soil, a hardness tester of the Revyakin system was used (Fig. 2). The density of the soil in the traces of the technological track was measured with a densitometer of our construction, and the humidity was measured with a moisture meter MG-44 (Fig. 2). 


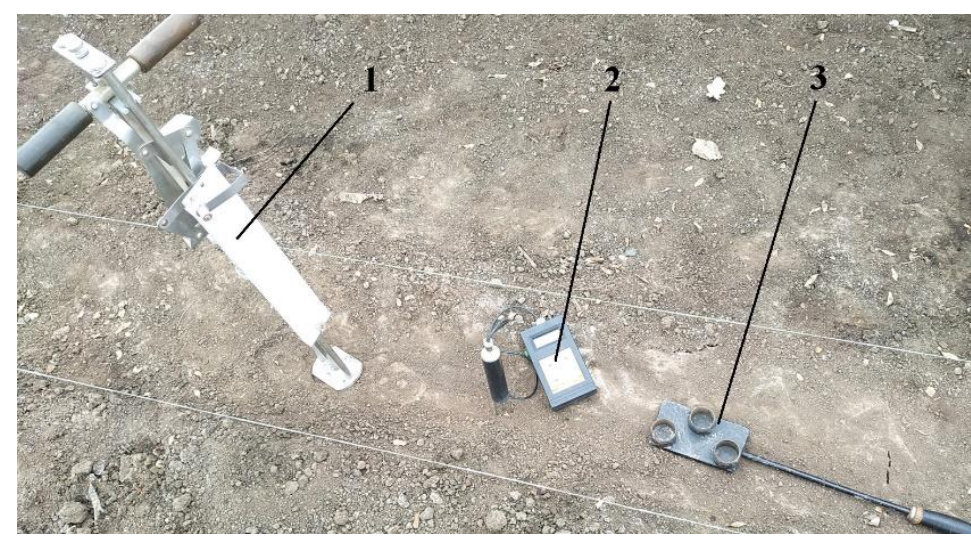

Fig. 2. Measuring devices for determining the physical and mechanical properties of the soil in the traces of a constant technological track: 1 - hardness tester Revyakin system; 2 - moisturemeter MG44; 3 - densitymeter

To exclude the random component of error, the determination of physical and mechanical parameters of the soil in the traces of a constant technological track experiments were performed repeatedly. The obtained values of indicators were averaged. The error of direct experimental measurement of parameters by the devices presented in fig. 2 , did not exceed $2 \%$.

Research results and discussion. The study of the properties of soil traces of a constant technological track showed that the values of such indicators as density and hardness in the layer $0 . . .5 \mathrm{~cm}$ significantly depend on humidity. With increasing humidity of the soil track track from 10 to $45 \%$ the value of density $\rho$ in it decreases from 1.60 to $1,30 \mathrm{~g} \cdot \mathrm{sm}^{-3}$ (Fig. 3).

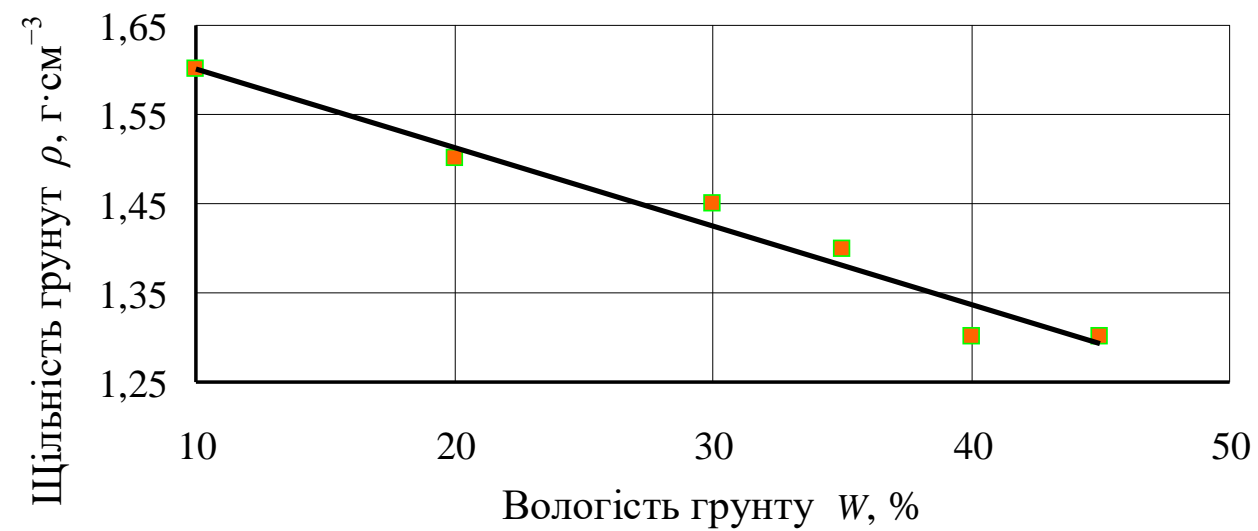

Fig. 3. Density dependence $\rho$ of the soil trace of a constant technological track from humidity $W$

A similar picture can be observed when changing the value of the hardness of soil traces of a constant technological track from its humidity (Fig. 4).

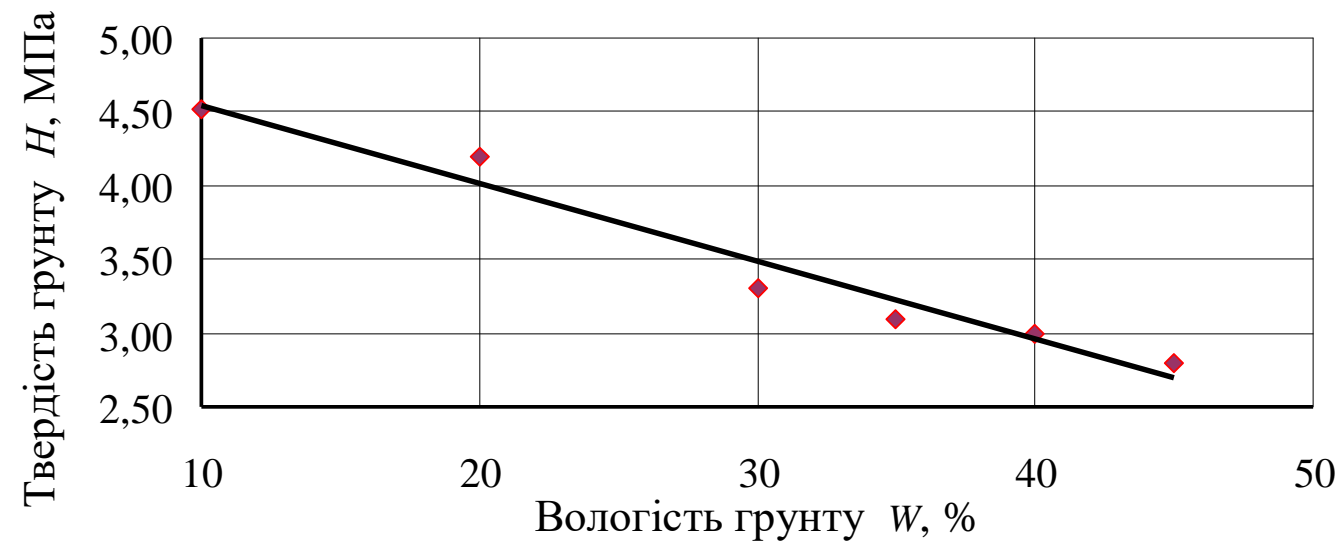

Fig. 4. Dependence of the hardness of the soil trace of the constant technological track on moisture 
From the analysis of the graph presented in Fig. 4 it is necessary that with the increase of humidity of track traces from 10 to $45 \%$ the value of soil hardness in the track decreases from 4.5 to $2.8 \mathrm{MPa}$.

The nature of the dependence of indicators in Fig. 3 and Fig. 4 is linear. The square of the correlation coefficients of their relationships is quite high and is $R^{2}=0,96$.

The relationship between the density of soil traces of a constant technological track with its hardness is presented in Fig. 5.

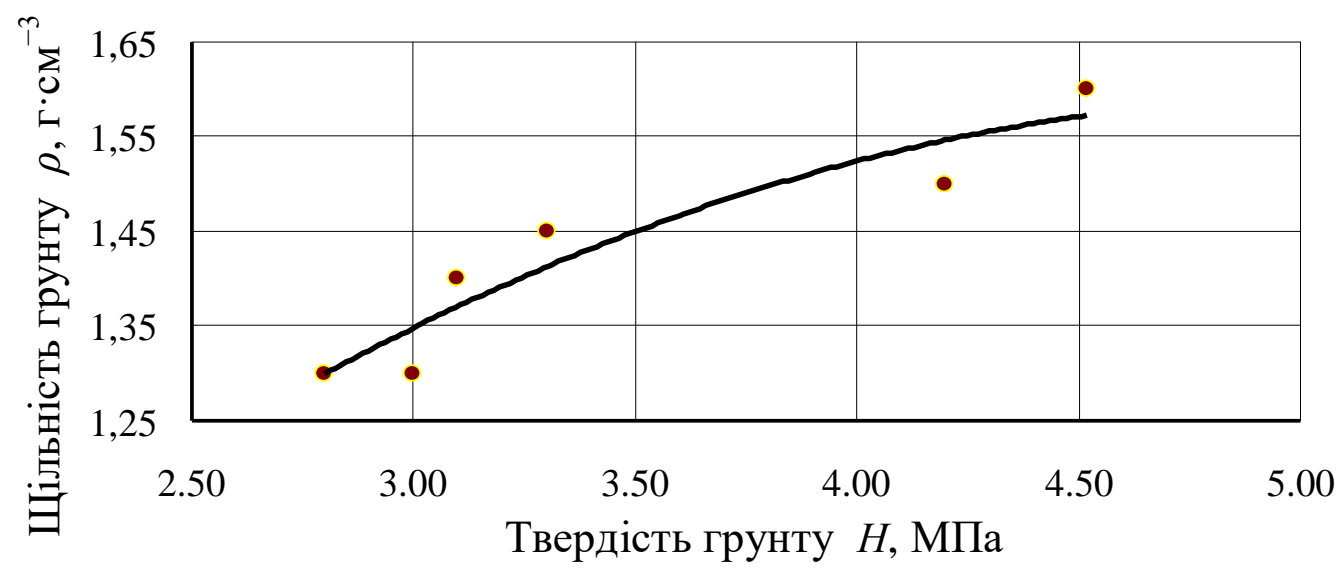

Fig. 5. Dependence of the density of the soil trace of the constant technological track on the hardness $H$

Analysis of the graph presented in Fig. 5 shows that there is a high nonlinear correlation between the density and hardness of the soil trace of a constant technological track. The square of the correlation coefficient between these indicators is $R^{2}=0,89$, which is much lower than the values of the correlation coefficients. This proves that the results of hardness measurements can predict the density of traces of a constant technological track and vice versa.

The relationship between the indicators presented in Fig. 5 , is fairly accurately approximated by an expression of this kind:

whele $\rho-$ soil density in the traces of a constant technological track, $\mathrm{g} \cdot \mathrm{sm}^{-3}$; $H$ - soil hardness in the traces of a constant technological track, determined by the Revyakin system, MPa.

Next, we evaluate the impact of physical and mechanical properties of the soil trace of the constant technological track on the quality of adhesion and traction of the bridge agricultural unit. To do this, the maximum tangential thrust force that develops the wheel of the bridge agricultural tool, we present the following dependence [11]:

$$
P_{k \max }=\delta_{\max } \cdot S_{k} \cdot k_{0} \cdot L
$$

where $\delta_{\max }$ - the maximum slip coefficient of the engines of the bridge agricultural unit; $S_{k}$ - sum of vertical projections of thrust surfaces submerged in the ground by ground hooks of the wheels of the bridge agricultural unit, $\mathrm{m}^{2} ; k_{0}$ - the coefficient of volumetric folding of the bearing surface of the wheel (a trace of a constant technological track), $\mathrm{N} \cdot \mathrm{m}^{-3} ; L$ - the length of the arc of adhesion of the soil hooks of the wheel of the bridge agricultural unit with the supporting surface (following the constant technological track), $\mathrm{m}$.

Also, the coupling of the wheel of the bridge agricultural tool with a trace of a constant technological track must be sufficient for it to be able to develop the maximum tangential traction force [1]:

$$
P_{k \max }=\varphi \cdot N_{e k},
$$

where $\varphi$ - the coefficient of adhesion realized by the engine of the bridge agricultural unit under the conditions of its interaction with the bearing surface; $N_{e k}$ - vertical operating load acting on the wheel of the bridge agricultural unit, $\mathrm{N}$.

Then, equal to expressions (2) and (3), we have:

$$
\delta_{\max } \cdot S_{k} \cdot k_{0} \cdot L=\varphi \cdot N_{e k} .
$$

Expressions to determine the values $L$ and $S_{k}$ will have this form [11]: 


$$
L=\left(r_{0}+h_{z}\right)\left(\operatorname{arctag} \frac{f_{k}\left(1-f_{k}^{2}\right)^{\frac{1}{2}}}{\frac{1}{2}-f_{k}^{2}}+2 f_{k}^{2}\right),
$$

and

$$
S_{k}=\pi \cdot h_{z}\left[\left(2 r_{0}-h_{z}\right) \cdot\left(b_{0}-h_{z}\right)\right]^{\frac{1}{2}},
$$

where $r_{0}, b_{0}$ - respectively static radius and wheel width of the bridge agricultural unit, $\mathrm{m} ; f_{k}$ - coefficient of rolling resistance of the wheel of the bridge agricultural unit; $h_{z}-$ normal tire deflection [11], $\mathrm{m}$ :

$$
h_{z}=\frac{N_{e k}}{\pi \cdot \rho_{w} \cdot \sqrt{2 r_{0} \cdot b_{0}}},
$$

where $\rho_{w}$ - tire pressure, $\mathrm{Pa}$;

Earlier researches of work of a wheel of the bridge agricultural unit on a soil trace of a constant technological track carried out by us have allowed to establish analytically enough exact dependence of value of coefficient $k_{0}$ its volumetric crumple from the value of hardness $H$ :

$$
k_{0}=\frac{0,636 \cdot N_{e k}}{b_{0} \cdot 4 r_{0}^{2} \cdot\left(0,0247 \cdot H^{2}-0,2093 \cdot H+0,499\right)^{3}} .
$$

Also we have established that the rolling resistance coefficient $f_{k}$ of the wheel of the bridge agricultural unit depends on the physical and mechanical properties of the soil track of a constant technological track. In particular, depending on its hardness $H$ the rolling resistance coefficient $f_{k}$ is quite accurately described by the quadratic dependence of the following type:

$$
f_{k}=0,0247 \cdot H^{2}-0,2093 \cdot H+0,499 .
$$

After substitution of expressions (5) - (9) in (4), we will have a calculated mathematical model, which allows us to study the processes of gravitation of the wheel of the bridge agricultural unit depending on the constructive parameters on the one hand and physical and mechanical properties of the traces of a constant technological track on the other hand.

On the basis of the given mathematical model, by means of calculations on the PC, the received graphic dependence of necessary pressure $\rho_{w}$ of air in tires of wheels of bridge agricultural unit from hardness $H$ of a soil track of a constant technological track (fig. 6).

From the analysis of the specified schedule it is necessary that the higher hardness of traces of a constant technological track, the more high air pressure it is expedient to have in the tire.

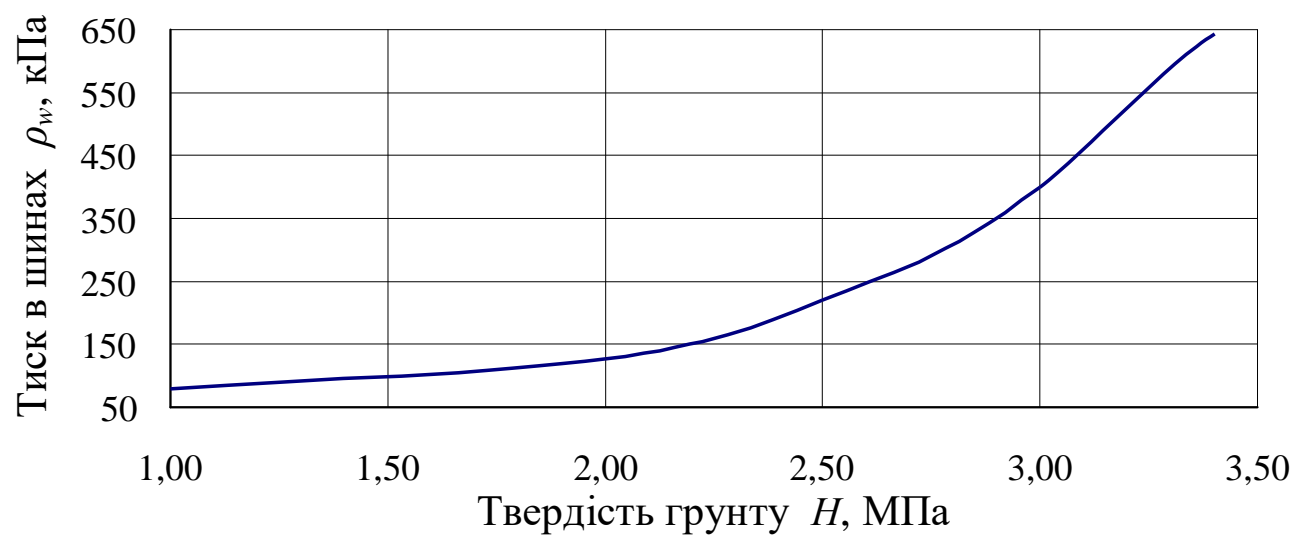

Fig. 6. Dependence of the required air pressure in the axle wheels of the agricultural unit on the hardness $H$ of the soil track of a constant tramline

Moreover, with increasing hardness of the traces of the constant technological track from 1.0 to $3.5 \mathrm{MPa}$, the air pressure in the tire of the wheels of the bridge agricultural vehicle must be increased from 60 to $650 \mathrm{kPa}$, ie 10 times. Naturally, the value of the maximum possible air pressure in the tire is determined by its technical characteristics. For the specified brand of tire used in this bridge agricultural unit, this value is $160 \mathrm{kPa}$. Therefore work of the bridge agricultural unit with the maximum pressure in tires is possible only at hardness of traces of a 
constant technological track of 2,25 MPa and above. However, at lower hardness of the soil track, the air pressure in the tire of its wheels must be reduced. This allows to ensure high traction-coupling properties of the bridge agricultural unit during its movement on the soil track of the constant technological track. For example, when the value of hardness $H=1 \mathrm{MPa}$, the value of pressure $\rho_{w}$ in the tire the wheel should be $80 \mathrm{kPa}$.

The obtained dependence of the value of the required pressure in the wheels tires of the bridge agricultural unit on the hardness of the soil trace of the constant technological track (Fig. 6) summarizes the condition under which its maximum coupling properties are achieved.

The conducted researches confirm the fact that the maximum efficiency of movement of the bridge agricultural tool on soil traces of a constant technological unit can be reached only in case of correctly established air pressure in tires of its wheels. The value of the latter, in turn, depends on the physical and mechanical properties of the soil trace of the constant technological track.

\section{Conclusions}

The study of the properties of soil traces of a constant technological track showed that the values of density and hardness in the layer $0 \ldots 5 \mathrm{~cm}$ significantly depend on humidity. With increasing humidity of the soil track from 10 to $45 \%$, the value of density in it decreases from 1.60 to $1,30 \mathrm{~g} \cdot \mathrm{sm}^{-3}$, and hardness - from 4.5 to $2.8 \mathrm{MPa}$.

A high nonlinear correlation between the hardness and density of the soil trace of a constant technological track, which is approximated by a quadratic dependence, has been experimentally established. Its practical use allows to predict the value of the density of traces of a constant technological track based on the results of hardness measurement and vice versa.

From the standpoint of providing maximum traction properties and traction of the bridge agricultural unit during its movement on the soil track of a constant technological track, it is established that increasing the hardness of the latter requires increasing the air pressure in the tire of its wheels and vice versa.

The conducted researches confirm the fact that the maximum efficiency of movement of the bridge agricultural tool on soil traces of a constant technological track can be reached only in case of correctly established air pressure in tires of its wheels. The value of the latter, in turn, depends on the physical and mechanical properties of the soil trace of the constant technological track.

\section{References}

1. Kutkov, G. (2014). Tractors and Automobiles: the theory and the technological properties. Moscow. [In Russian].

2. Bulgakov, V., Velichko, I., \& Ivanovs, S. (2016). Investigation of draft coefficient of efficiency of wheeled tractor. Engineering for rural Development, 2016-January, 1036-1041.

3. Panchenko, A., \& Kyurchev, V. (2008). A study of the draft and coupling qualities of wheeled tractors. Proceedings of the Taurida State Agrotechnological University, 8(9), 31-36. [In Ukrainian].

4. Nadykto, V., Arak, M., \& Olt, J. (2015). Theoretical research into the frictional slipping of wheel type undercarriage taking into account the limitation of their impact on the soil. Agronomy Research, 13(1), 148-157.

5. Nadykto, V. T., \& Velychko, O. V. (2015). Forecasting the development of energy ratio of agricultural tractors. Mechanization and electrification of agriculture, 1(100), 147-151. [In Russian].

6. Nadykto, V., Bulgakov, V., Kyurchev, S., Nesvidomin, V., Ivanovs, S., \& Olt, J. (2019). Theoretical background for increasing grip properties of wheeled tractors based on their rational ballasting. Agraarteadus, 30(2), 78-84.

7. Vasiliev, S. I. (2007). Improvement of the method and technical means for horizontal measurement of soil hardness with the introduction of coordinate farming technology: author. dis. PhD: 05.20.01. Penza. [In Russian].

8. Kushnarev, A., Kravchuk, V., Kushnarev, S., \& Dyuzhaev, V. (2010). Monitoring of soil density of arable horizon in the system of precise (controlled) agriculture. Technique and technology of the agro-industrial complex, 9, 12-15. [In Russian].

9. Nadykto, V., \& Uleksin, V. (2008). The controlled and the gantry systems of farming. Monograph. Kyiv. [In Ukrainian].

10. Bulgakov, V., Kuvachov, V., \& Olt, J. (2019). Theoretical study on power performance of agricultural gantry systems. Proceedings of the 30th International DAAAM Symposium "Intelligent Manufacturing \& Automation", 23-26th October 2019. Published by DAAAM International, Vienna, Austria, EU, Zadar, Croatia. (Vol. 30, No. 1, pp. 0167-0175).

11. Guskov, V. V. (1996). Optimal parameters of agricultural tractors. Moscow. [In Russian]. 